\title{
Obsessive Jealousy Masquerading as Delusional Disorder
}

\author{
Sreelatha Pasupuleti ${ }^{1}$, Bhavya Sree Rayachoti ${ }^{2}$
}

\begin{abstract}
Jealousy and morbid jealousy are the phenomena commonly encountered by psychiatrists. Its significance extends beyond the clinical characteristics and treatment to forensic aspects as well. This jealousy results in behaviors designed to prevent partner infidelity and to retain their romantic partners. These retention behaviors can be both nonviolent and violent and differ in males and females. Morbid jealousy is a symptom with different psychopathological presentations resulting in distinct psychiatric diagnosis and treatment. Obsessive jealousy in particular needs special consideration as it goes unrecognized or more often be mistaken for delusional jealousy. In contrast to delusional jealousy which expresses itself with the strong degree of conviction of partner's infidelity, obsessive jealousy presents as recurring, unpleasant, undesired, unwanted, and irrational thoughts of their partner's infidelity. In obsessive jealousy, the individual suffers from a possibility of unfaithfulness which can be sexual and emotional with resultant monitoring behaviors.

Keywords: Delusional jealousy, Forensic psychiatry, India, Mental health, Morbid jealousy, Obsessive-compulsive disorder.

Indian Journal of Private Psychiatry (2021): 10.5005/jp-journals-10067-0088
\end{abstract}

\section{INTRODUCTION}

Jealousy is a common yet complex emotion. Though the oxford dictionary defines jealousy as a feeling of resentment displayed onto a person considered as rival. This may not fully encapsulate the various aspects of jealousy, which usually includes an array of behavioral, affective, and cognitive responses in relation to fear of losing a valued relationship to a rival or losing the affection of one's partner. ${ }^{1,2}$ It comprises three important characteristics-the existence of a real or imaginary rival, perceived threat of losing a loved one to the rival, and a reaction to eliminate the threat. ${ }^{3}$ Jealousy differs from envy in that it occurs in the context of a third person. Hatred is projected onto the third person and blamed for the loss of someone's affections.

Jealousy can range from normalcy to pathological depending on the intensity, reasonability, persistence, and the irrationality of the perceived threat. ${ }^{4}$ Normal jealousy is an understandable and appropriate reaction to partner's unfaithfulness. In this context, the jealous partner has the ability to modify his or her beliefs and reactions if new information surfaces contradictory to the originally held thoughts. In pathological jealousy, individuals tend to rely on irrelevant clues as evidence of unfaithfulness, and they are unable to substantiate their conclusions and hold on to their beliefs even when evidence contrary to their beliefs is provided. It is an excessive and irrational response with no valid basis. ${ }^{5}$ Pathological jealousy or morbid jealousy can occur in multiple psychiatric disorders, including alcohol dependence, schizophrenia, affective disorders, delusional disorders, personality disorders, and obsessivecompulsive disorder (OCD).

The consequences of morbid jealousy are multifold from relationship dissatisfaction, verbal and physical abuse, homicide/ suicide, restrictions of the partner's autonomy, and stalking the partner. In pathological jealousy, the psychopathology is the preoccupation with the partner's sexual infidelity. This psychopathology can take the form of delusion, obsession, or overvalued idea. Differentiating among them is helpful for an appropriate diagnosis and subsequent management of the case. We are presenting a case of obsessive jealousy initially diagnosed as delusional disorder.
${ }^{1,2}$ Department of Psychiatry, PES Institute of Medical Sciences and Research, Kuppam, Andhra Pradesh, India

Corresponding Author:Sreelatha Pasupuleti, Department of Psychiatry, PES Institute of Medical Sciences and Research, Kuppam, Andhra Pradesh, India, Phone: +91 9663399840, e-mail: drsreelathakumar@ gmail.com

How to cite this article: Pasupuleti S, Rayachoti BS. Obsessive Jealousy Masquerading as Delusional Disorder. Ind J Priv Psychiatry 2021;15(2):101-102.

Source of support: Nil

Conflict of interest: None

\section{Case Description}

A 36 years old female with secondary school education, homemaker, from a rural background consulted the psychiatry department with her friend. She presented with fear that her husband is having an extramarital affair with other women in the neighborhood since 5 years. Since 4 years, she has been monitoring her husband's activities especially in and around the home, reports of her husband sending special nonverbal signals to other women to generate their sexual interest toward him. She has been taking her children help to spy on him, to follow him whenever her husband goes to work, and report about his activities back to her. She herself has been repeatedly checking her husband's phone, whenever she sees an unknown contact or unknown female contact she would question him about the call and the details of the conversation. She had arguments with her female neighbors accusing them of seducing her husband. The patient elaborated that whenever her husband wore a specific color of clothing, the females in the neighborhood also wore the same color of clothing. Also, her husband sells dairy products like milk in plastic cans. Whenever he places the milk cans in a specific manner, he is signaling to women that he is sexually interested in them. With this, a provisional diagnosis of delusional disorder was made in outpatient and the patient was requested to report back with her husband for further clarification. In the follow-up visit, the husband reported that the patient believes he

(c) The Author(s). 2021 Open Access This article is distributed under the terms of the Creative Commons Attribution 4.0 International License (https://creativecommons. org/licenses/by-nc/4.0/), which permits unrestricted use, distribution, and non-commercial reproduction in any medium, provided you give appropriate credit to the original author(s) and the source, provide a link to the Creative Commons license, and indicate if changes were made. The Creative Commons Public Domain Dedication waiver (http://creativecommons.org/publicdomain/zero/1.0/) applies to the data made available in this article, unless otherwise stated. 
was unfaithful though he never cheated on her since their marriage. He confirmed that the patient had quarreled with a woman in the neighborhood accusing her of having sexual relationship with him and neighbors alerted him that there may be legal implications if this isn't addressed. The patient was hospitalized and started on Tab. Risperidone $2 \mathrm{mg}$ along with Tab. Chlordiazepoxide for her agitation and sleep disturbances. A detailed evaluation was done on day 2 following hospitalization and further clarifications on the psychopathology were sought. As reported by the patient, her fear is of repeated thoughts that her husband may be indulging in sexual activities in which the patient finds distressing and tries to resist them without success. Repeatedly, the patient tried to explain that she trusts her husband that he was not unfaithful and that she knows that her husband is not involved in any affairs. She doesn't understand the reason of her repeated thoughts on the same matter. Whenever she gets these thoughts, she questions her husband and his reassurance relieves her thoughts. Also, she prays to god to overcome her thoughts which bring some temporary relief. Her checking on her husband's activities and whereabouts also brings some relief. She is occupied with the fear of losing her husband eventually to some other women. The patient had no significant past or family psychiatric history with any known medical comorbidities. Her physical examination revealed no abnormalities. Mental status examination shows her to be conscious, alert, and cooperative with anxious affect, obsessions of doubts, and compulsion of checking and praying. Her cognitive functions and judgment were intact. Her blood workup and neuroimaging of the brain were normal. YBOCS (score - 31) showed severe OCD and HAM-A scoring revealed mild to moderate anxiety on day 2 of hospitalization. Hence, the diagnosis was revised to OCD on day 3 of hospitalization and Risperidone discontinued tab. Fluoxetine was started at $20 \mathrm{mg}$ OD which was gradually increased to $80 \mathrm{mg}$ at the time of discharge with Tab. Chlordiazepoxide continued and increased to $30 \mathrm{mg}$ due to persistent complaints of sleep disturbances which were reduced to $10 \mathrm{mg}$ at the time of discharge. The duration of the hospital stay was 28 days. YBOCS score the day prior to discharge was moderate OCD (score-12). Psychological interventions initiated during hospitalization were JPMR and Exposure and Response prevention techniques done twice a week during hospitalization by a junior resident, improvement of theses interventions assessed by rating scales, and clinical improvement as reported by the patient.

After the discharge, the patient has been compliant with medication with regular outpatient visits to psychiatry for 6 months following discharge. During her follow-up visits after 3 months of discharge, the patient reported a significant improvement in her obsessions, compulsions, and fear of losing her partner (YBOCS-3).

\section{Discussion}

The distinction of normal from pathological jealousy is difficult and it poses a challenge to the treating clinicians to set the boundaries and delineate the different types of jealousy. ${ }^{5}$ Jealousy can take a morbid form if its degree of possessiveness is beyond the societal and cultural norms. ${ }^{3}$ Whether normal or morbid, jealousy usually involves a concoction of emotional display of pain, insecurity, mistrust, humiliation, hostility, anger over betrayal, and fear of abandonment. ${ }^{6}$ Pathological jealousy is a common clinical entity yet difficult to treat. This can partially be due to challenges posed in differentiating between delusional and nondelusional jealousy which includes obsessive jealousy. Though literature abounds on delusional jealousy popularly also known as Othello syndrome, obsessional jealousy is usually under recognized and the distinct phenomenology of this type of jealousy of OCD is not scrutinized as often. This form not only presents as jealousy in the form of obsessional ideation which are egodystonic but also compulsions of checking, interrogation, seeking reassurances from a partner about their fidelity, and excessive sexual demands on a spouse. The course is observed to be waxing and waning with a good response to antidepressants rather than antipsychotics. ${ }^{7}$ Distinguishing and identification of obsessive jealousy are not just of phenomenological interest but have implications in the kind of interventions to be initiated. Adding to the existing dilemma, another component of the obsessional jealousy variant has been identified known as relationship OCD which features ideas, doubts, and urges in their romantic relationships. It is focused on one's feelings toward a relationship partner, the partner questioning the relationship. ${ }^{8}$ This conundrum can be tackled by specific research on different variants of obsessional jealousy not just at the level of clinical presentation but from a neurobiological perspective too.

\section{Conclusion}

Jealousy in itself is to be considered as an alarm signal that warns of an imminent threat if not adequately evaluated. This calls for vigilance in assessing the individual, in making an appropriate and early diagnosis. The amount of distress caused by obsessive jealousy to both the partners involved and the immediate family and the serious consequences thereof if left unattended cannot be underestimated. The various terminologies used to describe morbid jealousy and that the well-known rating scale to assess OCD, the Y-BOCS scale's failure to include assessment of jealous obsessions further elevates the confusion of the treating psychiatrist. Hence, the need for postulating defining criteria and standardized assessment tools for obsessional jealousy.

\section{References}

1. Kingham, M Gordon, $\mathrm{H}$ (2004). Aspects of morbid jealousy. Advances in Psychiatric Treatment, 10(3): 207-215. DOI:10.1192/apt.10.3.207.

2. Pfeiffer SM, Wong PTP. Multidimensional Jealousy. Journal of Social and Personal Relationships. 1989;6(2):181-196. DOI:10.1177/ 026540758900600203.

3. Mullen PE. Jealousy: the pathology of passion. Br J Psychiatry. 1991;158:593-601. DOI: 10.1192/bjp.158.5.593.

4. Marazziti D, Consoli G, Albanese F, et al. Romantic attachment and subtypes/dimensions of jealousy. Clin Pract Epidemiol Ment Health. 2010;6:53-58. DOI: 10.2174/1745017901006010053.

5. Batinic B, Duisin D, Barisic J. Obsessive versus delusional jealousy. Psychiatr Danub. 2013;25(3):334-339. PMID: 24048408.

6. Ecker W. Non-delusional pathological jealousy as an obsessivecompulsive spectrum disorder: Cognitive-behavioural conceptualization and some treatment suggestions. J Obsessive Compulsive Related Disorders 2012;1:203-210. DOI: 10.1016/J.JOCRD.2012.04.003.

7. Cobb JP, Marks IM. Morbid jealousy featuring as obsessive-compulsive neurosis: treatment by behavioral psychotherapy. Br J Psychiatry. 1979;134:301-305. DOI: 10.1192/bjp.134.3.301.

8. Doron G, Kyrios M. Obsessive compulsive disorder: a review of possible specific internal representations within a broader cognitive theory. Clin Psychol Rev. 2005;25(4):415-432. DOI: 10.1016/ j.cpr.2005.02.002. 